\title{
Models and theories of care applicable to predicting and improving adherence behaviours among
} Chronic Kidney Disease (CKD) patients

Geldine Chironda ${ }^{1,2 *}$, Busisiwe Bhengu ${ }^{1,2,3}$, Ancia Manwere ${ }^{4}$

${ }^{1}$ Rory Meyers College of Nursing, New York University, New York, New York. 001, US A

${ }^{2} S$ chool of Nursing and Midwifery, College of Medicine and Health Sciences, University of Rwanda, Kigali, Rwanda

${ }^{3}$ School of Nursing and Public Health, College of Health Sciences, University of KwaZulu-Natal, Durban, South Africa

${ }^{4}$ Faculty of Health Sciences, Bindura University of Science Education, Bindura, Mashonaland Central, Zimbabwe

*Corresponding author: Geldine Chironda, School of Nursing and Midwifery, College of Medicine and Health Sciences, University of Rwanda, 11 KG Avenue 47, Kigali, Rwanda email:gerrychironda@yahoo.co.uk

\begin{abstract}
Introduction: Models which relate to cognitive variables and processes may apply to adherence behaviours in patients with chronic conditions. Management of Chronic Kidney Disease (CKD) requires incorporation of these models to facilitate the positive adherence behaviours among patients.

Aim: This article critiques models and theories of care applicable to predicting and improving adherence behaviours among patients with chronic kidney disease (CKD).

Methods: Medline, Ebsco, PubMed, Google Scholar, Cinahl and grey literature were used to identify the relevant articles from the years 1990-2018. A conclusive search was done using the following key words: Models OR 'Theories of care AND Prediction [tab]' AND Improving AND adherence behaviours AND Chronic Kidney Disease

Results: The search identified 23 articles containing information on models and theories of care applicable to the management of CKD patients. The Common-Sense Model, Orem Self-care and Theory of Planned Behaviour Models were applied in predicting and improving adherence among CKD patients. Other identified possible models in predicting and improving adherence included Tran's Theoretical Model, the Theory of Reasoned Action, and the Social Cognitive and Health Belief Models.

Conclusion: These theories and models provide a baseline assessment regarding predicting and improving adherence in chronic kidney disease patients. However, there is no model or theory which comprehensively explains an understanding of predicting and improving adherence of CKD patients to their management, hence the need to consider the available models/theories to effectively engage CKD patients with their integrated management to promote the highest level of adherent behaviour.
\end{abstract}

$\overline{\text { Key words: Models/theories of care, prediction, adherence, Chronic Kidney Disease stages } 1 \text { to } 5 .}$

\section{Introduction}

Chronic Kidney Disease (CKD) refers to structural or functional abnormalities of the kidney which results in continual decrease in glomerular filtration rate (GFR) and abnormalities in blood and urine tests within a period of more than three months.[1] Management of CKD centres on renal replacement therapy (RRT), medication, diet and strict control of fluid intake.[2] Poor adherence to dialysis, medication, diet and fluid control is seen in almost half of the patients treated for $\mathrm{CKD}$ yet this is the only lifesaving management for these patients.[3]

Non-adherence is a pervasive problem and a significant barrier to the effective management of patients with
CKD. Evidence from literature highlights that the issue of non-adherence relates to medications, dialysis, and dietary and fluid restrictions among patients with CKD[4]. Therefore, patients with CKD require complex care irrespective of where they fit in the disease continuum. [5] Graham highlights the incorporation of the Orem, Neuman and Peplau Models into the clinical care of patients with CKD as a key aspect that enhances their overall care.[5] However, this is not recognised by clinical nurses because of their limited knowledge on how to incorporate the models into their care plans. Models assist in behaviour change interventions by promoting an understanding of adherence health behaviour and facilitating the transferability of an intervention from one health issue to another.[6] 
Models which relate to cognitive variables and processes have been applied to adherence behaviour.[7]These include the Health Beliefs Model[8], Social Cognitive Theory,[9] Theory of Planned Behaviour[10], Theory of Reasoned Action,[11] Orem Self-care,[12] Tran's Theoretical Model,[13] Common Sense Model[14] and the Extended Parallel Process model.[15] The afore mentioned theories and models focus on how patients view health threats, while at the same time appraising the facilitating and inhibiting factors of adherence. [16] Moreover, these models/theories also involve behavioural intentions and actual behaviour as dependent variables and do not only focus on determinants.

Maximum adherence to medication, dialysis treatments and fluid and dietary restriction is necessary in CKD patients, however, interventions to facilitate this concept are not well researched.[17] Patient medication adherence continues to be an evolving area among CKD patients, nevertheless, the available literature on this concept is limited.[18] Further, there is no summative analysis of theories and models applicable to predicting and improving adherence among CKD patients. There is also no single model or theory which comprehensively provides an understanding of predicting and improving adherence of CKD patients to their management.

\section{Aim}

The aim of the analysis is to evaluate the applicability of identified models and theories of care in predicting and improving adherence behaviours among patients with Chronic Kidney Disease (CKD).

\section{Methods}

Data Bases: A conclusive search was done to identify studies with models and theories of care which are applicable to predicting and improving adherence behaviours among CKD patients. Medline, Ebsco, PubMed, Google scholar, Cinahl and grey literature were used to identify the articles. The search for articles included in the review is shown in Figure 1.

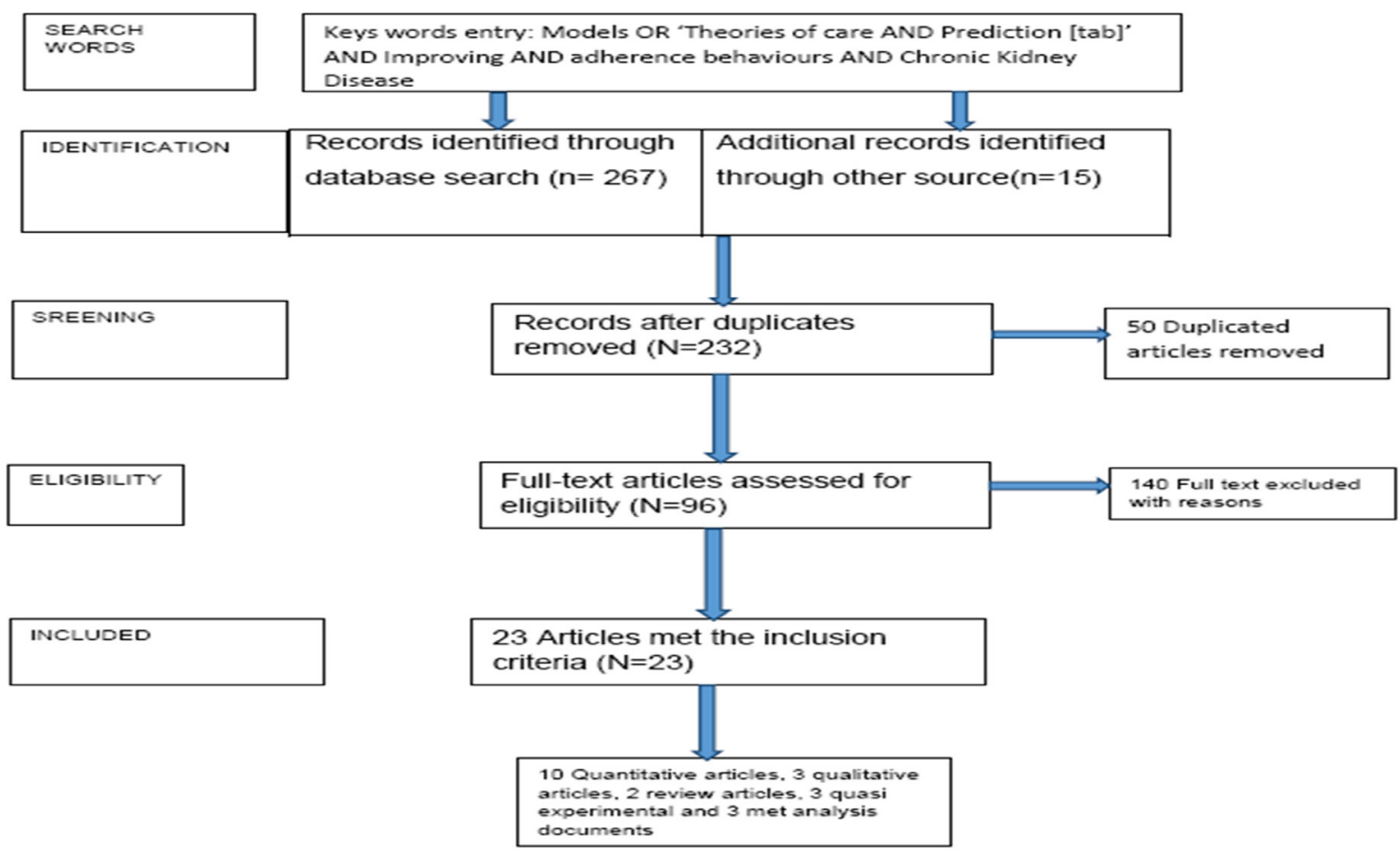

Figure 1. Diagram showing flow of search strategy

Inclusion criteria: The search included all patients with CKD stages 1 to 5 on or not on dialysis. Only English language papers published between January 2000 and 2017 were included in the review. Qualitative articles were included in the review as they narrated and explained the models and theories of care. Articles which were quantitative in nature were included as they had tested the models and theories statistically using inferential statistics to predict the adherence behaviours among patients with CKD. Meta-analysis studies on theories and models were included in this review because they contained both quantitative and qualitative articles which had been tested statistically to predict and improve adherence behaviours. Narrative review articles were also included.

Exclusion criteria: Editorials, letters and comments were also isolated from the review. All duplicated articles were excluded in the screening phase. 


\section{Results}

The search identified 23 articles containing information on models and theories of care applicable to the management of CKD patients, as shown in Table 1 and Table 2. Of the 23 articles, 14 studies were descriptive cross-sectional designs, 4 were meta-analyses, 3 were quasi-experimental designs, 1 was a randomised control trial and 1was a narrative review. The Common-Sense Model, Tran's Theoretical Model, the Theory of Reasoned Action, Social Cognitive Theory, Orem Selfcare, the Theory of Planned Behaviour, the Health Belief Model and the Extended Parallel Process Model have been applied in predicting and improving adherence among CKD patients.

\section{Table 1. Articles identified with models and theories of care applicable to CKD patients}

\begin{tabular}{ll}
\hline Authors & Study title and journal \\
\hline Fincham, D., Kagee, A., & Dietary and fluid adherence among haemodialysis \\
\&Moosa, R. (2008). & patients attending public sector hospitals in the \\
& Western Cape. South African Journal of Clinical Nutrition, \\
& 21(2), 7-12.
\end{tabular}

Sutton, S. (1998).

Predicting and explaining intentions and behavior: How well are we doing? Journal of applied social psychology, 28(15), 1317-1338.

Unsar, S., Erol, O., The self-care agency in dialyzed patients. Dialysis \& \&Mollaoglu, M. (2007). transplantation, 36(2), 57-70.

Clarke, A. L., Yates, T., Patient's perceptions of chronic kidney disease Smith, A. C., \& Chilcot, and their association with psychosocial and clinical J. (2016).

Knowles, S., Swan, L., Exploring the relationships between health status, Salzberg, M., Castle, D., illness perceptions, coping strategies and psychological \& Langham, R. (2014). morbidity in a chronic kidney disease cohort. The American journal of the medical sciences, 348(4), 271-276.

Hagger, M. S., \& Orbell, S. (2003).

Lin, C. C., Chen, M. C., Hsieh, H. F., \& Chang, S. C. (2013).

Wu, C. C., Lin, C. C., Hsieh, H. F., \& Chang, S. C. (2016).

McKillop, G., \& Joy, J. (2013).

A meta-analytic review of the common-sense model of illness representations. Psychology and health, 18(2), 141-184.

Illness representations and coping processes of Taiwanese patients with early-stage chronic kidney disease. Journal of Nursing Research, 21(2), 120-128.

Lived experiences and illness representation of Taiwanese patients with late-stage chronic kidney disease. Journal of health psychology, 21(12), 2788-2798.

Patients' experience and Perceptions Of Polypharmacy In Chronic Kidney Disease And Its Impact On Adherent Behaviour. Journal of renal care, 39(4), 200-207.

Meuleman, Y., de Goeij, Illness perceptions in patients on predialysis care: M. C., Halbesma, N., Chilcot, J., Dekker, F. W., van Dijk, S., \& PREPARE-2 Study Group. (2015).

O'Connor, S. M., Jardine, A. G., \& Millar, K. (2008).

McManus, M. S. (2011).

Elliott, J. O., Ortman, C., Almaani, S., Lee, Y. H., \& Jordan, $\mathrm{K}$. (2015). associations with time until start of dialysis and decline of kidney function. Psychosomatic medicine, 77(8), 946-954.

The prediction of self-care behaviors in end-stage renal disease patients using Leventhal's Self-Regulatory Model. Journal of psychosomatic research, 65(2), 191-200.

Illness representation and medication adherence of patients with chronic kidney disease. Indiana University.

Understanding the associations between modifying factors, individual health beliefs, and hemodialysis patients' adherence to a low-phosphorus diet. Journal of Renal Nutrition, 25(2), 111-120.

$\begin{array}{ll}\text { Study design } & \text { Study population } \\ \text { Descriptive } & \text { Haemodialysis patients }(\mathrm{N}=62)\end{array}$

Cross-sectional

Meta-analysis

Study population not applicable design

Descriptive cross

Dialysis patients (n-92)

sectional

Narrative review

Patients with CKD

Descriptive cross

sectional

Meta-analysis

45 empirical studied

Descriptive

15 early stage CKD patients

qualitative

Descriptive

15 late stage $\mathrm{CKD}$ patients

qualitative design

Descriptive

10 Chronic kidney Disease

qualitative design patients

Descriptive cross 416 predialysis patients

sectional design

Descriptive cross sectional design

Descriptive correlational design
Descriptive cross sectional survey
73 ESRD patients on haemodialysis

92 CKD stage 2 patients

95 CKD patients on haemodialysis 
Table 2. Articles identified with models and theories of care applicable to CKD patients

\begin{tabular}{llll}
\hline Authors & Study title and journal & Study design & Study population \\
\hline Clark, S., Farrington, & Nonadherence in dialysis patients: prevalence, & Review article & Dialysis patients \\
K., \& Chilcot, J. (2014, & measurement, outcome, and psychological & & \\
January). & determinants. In Seminars in dialysis (Vol. 27, No. 1, pp. & & \\
& $42-49)$.
\end{tabular}

Brandes, K., \& Mullan, Can the common-sense model predict adherence B. (2014).

Rich, A., Brandes, K., Mullan, B., \& Hagger, M. S. (2015).

Wileman, V., Farrington, Medication beliefs are associated with phosphate K., Wellsted, D., binder non-adherence in hyperphosphatemic

Almond, M., Davenport, haemodialysis patients. British journal of health psychology, A., \& Chilcot, J. (2015). 20(3), 563-578.

Vélez-Vélez, E., \& Bosch, R. J. (2016).

Fung, T. K., Ng, Y. L., Lam, M. F., \& Lee, K. K. (2017).

Bahadori, M., Ghavidel, F., Mohammadzadeh, S., \&Ravangard, R. (2014).

Jahanpeyma, P., \& Akbari, M. (2016).

Illness perception, coping and adherence to treatment among patients with chronic kidney disease. Journal of advanced nursing, 72(4), 849-863.

Psychosocial Factors Predict Nonadherence to PD Treatment: A Hong Kong Survey. Peritoneal Dialysis International, 37(3), 331-337.

The effects of an interventional program based on self-care model on health-related quality of life outcomes in haemodialysis patients. Journal of education and health promotion, 3

The Effect of Orem's Self-care Education on Interdialytic Weight and Blood Pressure Changes in Haemodialysis Patients. INTERNATIONAL JOURNAL OF MEDICAL RESEARCH \& HEALTH SCIENCES, 5(7), 294-299.

Motivational interviewing promotes adherence and improves wellbeing in pre-dialysis patients with

García-Llana, H., Remor, E., Peso, G., Celadilla, O., \&Selgas, R (2014).

Teng, H. L., Yen, M., Fetzer, S., Sung, J. M., \& Hung, S. Y. (2013).

Patterson, M. S., Umstattd Meyer, M. R., Beaujean, A. A., \& Bowden, R. G. (2014).

Effects of targeted interventions on lifestyle modifications of chronic kidney disease patients: randomized controlled trial. Western journal of nursing research, 35(9), 1107-1127.

Using the social cognitive theory to understand physical activity among dialysis patients. Rehabilitation psychology, 59(3), 278.
Meta-analysis

Patients with chronic illnesses

Descriptive cross sectional design
Descriptive cross sectional designs.

Quasi

32 haemodialysis patients

experimental

design

Quasi

experimental

Descriptive cross

42 Advanced Chronic Kidney sectional study Disease patients

Randomized 160 CKD patients

135 patients on haemodialysis

52 haemodialysis patients

control trial

Cross sectional 115 dialysis patients 


\section{Discussion}

Common Sense Model The Common-Sense Model (CSM) explains ways in which patients are conscious of and able to formulate interventions to cure their health threat. The concepts of this model include illness stimuli, illness representation, coping responses and appraisal.[14] Illness stimuli refer to the pool of somatic or symptomatic information which is either stored in the memory or given by external sources.[19] Cognitive and emotional attributes form illness representation which is explained in terms of cause, consequences, control, identity and timeline.[20] Coping strategies include approach coping (active seeking of advice, help or medicine) and avoidance coping (the denial of symptoms and/or diagnosis and refusal to seek help). [14] Following the implementation of coping strategies, either appraisal occurs as the individual determines that equilibrium has been restored or there is identification of failures and the need to develop and change their coping strategies. In addition, continuous feedback is integrated into the plan of intervention action and threat-progression. [14] Management of health stressors depends on how patients perceive their illness as these affect cognitive and behavioural strategies.[21] The illness schema is informed by understanding of the condition, information from others and perceptions of the past and current symptoms of the condition have identified the Common-Sense Model as a dynamic selfregulation model which informs the development of self-management interventions.[21,22] The developed interventions target various behaviours leading to improved management and consequently quality of life of CKD patients. The same authors explain CKD as a progressive disease in which a substantial number of physical and clinical manifestations are evident and these are seen by patients as detrimental effects of CKD.[21] Furthermore, illness perceptions are directly linked to the methods of adaptive and maladaptive coping.[23]

Reducing a health threat is the common goal when attempting to achieve positive clinical outcomes; therefore CKD patients need to adopt various coping measures such as healthy behaviour and religious support. [24] Adoption of healthy lifestyle is advocated following better understanding of the relationship between CKD and lifestyle factors by patients.[25] Lin et al. explained that a reduction in the rate of CKD progression can occur when patients change their lifestyle.[24] Clarke et al. assert that a positive sense of personal control among CKD patients may influence the course of their condition.[21] While Vélez-Vélez and Bosch echo the same sentiments, these authors also identify a poorer sense of personal control as a factor affecting adherence to treatment modalities of haemodialysis CKD patients. [26]

Mckillop and Joy did a qualitative study which revealed complex medication regimens and medication side effects as illness threats with consequences of medication non-adherence.[27] CKD patients report difficulty in attributing their physical symptoms to their $\mathrm{CKD}[24,28]$ and the specified clinical manifestations of CKD and the related medication use affect selfmanagement behaviours such as medication adherence and physical activity.[22] O'connor et al. assessed the utilisation of Leventhal's Common Sense Model in the prediction of dietary, medication and fluid regime selfcare behaviours among advanced CKD patients and the model was found to predict the adherence behaviours related to these factors.[29]

McManus, however, did a study to establish the relationship between illness perceptions and medication adherence in patients with CKD and determined that illness perceptions did not have any effect on medication adherence, i.e. there was no significant relationship between the two variables.[30] The reason for the nonsignificant relationship between these two factors was the use of skewed data which caused reduced variability in the distribution of the scores and consequently insufficient power to detect correlations with small and medium effects. In other words, there was a violation of the normality assumption.[30] Brandes and Mullan also found similar results and concluded the CSM as an inappropriate model for use in predictive studies of adherence.[31] Other studies have indicated illness perception as a factor in predicting medication, fluid and dietary adherence in advanced CKD patients,[29] however, there is a scarcity of information on just how much variance these perceptions can effect on adherent behaviours in these patients.[14] Mullan therefore recommends further research to explore the variance contributed by illness perceptions on non-adherent behaviour in patients with CKD.

Theory of Planned Behaviour The Theory of Planned Behaviour emanated from reasoned action with the components: perceived behavioural control, behavioural intention, attitudes, perceived power, and subjective and social norms.[32,33] Attitudes entails the consideration of the outcomes of performing the behaviour; behavioural intention encompasses the motivational factors that influence a given behaviour; and subjective norms relates to a person's beliefs about whether peers and people of importance to the person think he or she should engage in the behaviour.[32] Moreover, social norms are the customary codes of behaviour in a population with perceived power referring to the perceived presence of factors that may facilitate or impede the performance of a behaviour. Perceived behavioural control refers to a person's perception of the ease or difficulty of performing the behaviour of interest.[33] The additional component of perceived behavioural control in the Theory of Planned Behaviour predicts and establishes the relationship between the 
need to change behaviour and the actual behaviour [34], meaning that the relationship between intention to adhere and the actual adherence behaviour can be elicited among CKD patients. Finchman and Moosa revealed the Theory of Planned Behaviour (TPB) in the self-reported treatment adherence of haemodialysis patients in the South African context as only partially applicable.[35] The results revealed possible decreased medical complications and mortality as a result of improved adherence to the dietary and fluid restrictions among the haemodialysis population, [35] therefore the study concluded this theory as applicable in predicting dietary and fluid adherence among haemodialysis patients.

A met analysis tested the efficacy of the Theory of Planned Behaviour in predicting adherence to treatment in chronic illness and the results revealed a 33 percent variance of behavioural intentions towards nonadherence in chronic illness. Furthermore, the Theory of Planned Behaviour explained 9 percent of the adherence behaviour in the chronic illness population. [36] Additionally, this theory had been tested in other diseases and had proven to influence health seeking behaviours in malaria patients, [37] hence its applicability to the adherence behaviours of CKD patients. However, the main weakness of this theory is that it does not account for factors that are beyond an individual's voluntary control. Sutton reports that additional weaknesses of the Theory of Planned Behaviour lie in the conceptualisation and definition of the theory and in additional explanatory factors such as past experiences and environmental and economic factors.[38] This theory also depends on rational purposes, not taking into consideration the role of emotions and religious beliefs in behaviour, as emotions and religious beliefs are important in facilitating adherence behaviours in CKD patients. Finchman and Moosa realised this and recommended theoretical research to understand the predictors of adherence among CKD patients.[35]

Orem Self-care One of the models which facilitates care of CKD patients is Orem's Self-care Model. The three basic nursing systems in Orem's theory are the wholly compensatory nursing system, the partly compensatory nursing system and the supportive educative system.[12] According to Orem, the wholly compensatory system relates to individuals who are not able to be involved in any self-care actions hence they are totally dependent on nurses for their wellbeing. The partly compensatory system is a mutual relationship in which both the patient and the nurse are involved in the provision of care. Lastly, the supportive educative system relates to patients being able to perform their oriented therapeutic care with assistance from health care providers. [12]

The care of patients with CKD is complex as it starts from the early recognition of renal dysfunction and progresses to the terminal stages of $\mathrm{CKD}$ which require the urgent initiation of dialysis procedures. Unfortunately, most patients do not recognise this disease in its early stages due to the unavailability of information, as widespread information on kidney diseases has not been prepared and disseminated and the disease remains underreported, especially in low income countries.[39] This, coupled with the inaccessibility of health care centres for necessary check-ups and a shortage of knowledgeable health care professionals, worsens the situation and results in late stage diagnosis. $[40,41]$ Furthermore, there is a lack of social support from the families of these patients and peer pressure exacerbates the situation as the parties involved do not provide sound advice regarding adhering to the necessary treatments. Instead they advise on other measures like herbal treatments and encourage alcohol consumption which are both detrimental to the patient. This is unfortunate as Chironda and Bhengu determined that peer and family support motivate adherence to the integrated management regimes of patients with CKD. [42]

CKD patients are expected to actively participate in and adhere to their care regimes in the early days following their diagnosis. Adhering to the recommended treatment from early on in the disease will lessen its progression to the terminal stages, reduce complications, prolong life and increase the chances of getting a kidney transplant. Unsah et al. echo the same sentiments and further emphasise the importance of self-care in dialysed patients as this maintains their quality of life and prevents complications.[43] The implementation of a Self-care Model as an intervention has revealed improved quality in terms of physical, social and mental functioning among haemodialysis patients[44] and another intervention programme of self-care concluded decreased intradialytic weight between two dialysis sessions among haemodialysis patients who had gone through the self-care teaching programmes. [45]

Unsah et al. did a study to evaluate the impact and effectiveness of self-care on the outcomes of CKD patients on both forms of dialysis, which included the associated factors that influenced the patients' actions. [43] Their results revealed that moderate self-care activities were not associated with any demographic characteristics in these dialysed patients.[43] These authors recommended the introduction of dialysis compliance programmes to aid patients in coping with the physical, social and psychological changes which occur as a result of dialysis.[43] Orem's view of health is fixed and constant, that is there are three static conditions of health while health itself is seen as dynamic and always changing. Orem's theory is therefore illness-oriented rather than wellness-oriented. From this viewpoint, adherence to management among CKD patients is more wellness-oriented and requires 
their active participation /involvement in their own care related to their recommended medication, dialysis and control of their fluid and food intake. Active participation of patients promotes the achievement of patient-centred care and empowerment, leading to a better quality of life for these patients. [46] It is therefore difficult to use this model alone to predict and improve adherence behaviours among CKD patients.

Theory of Reasoned Action The Theory of Reasoned Action predicts consumer intentions and behaviour and provides the basis for identifying target consumers. [11] The model reveals a socio-psychological approach in understanding and predicting the determinants of health behaviour. [10] According to Hale, the aim of the model is to explain volitional behaviours and its explanatory scope excludes a wide range of behaviours which include spontaneous, impulsive or habitual behaviours.[47]

According to this theory, behavioural intention is the central predictor of behaviour and theorists of reasoned action centre on the prediction of behavioural intention rather than on the behaviour itself.[48] In the context of a health-related behaviour situation such as adherence behaviour among CKD patients, most adherence behaviour is influenced by emotions and affect, which is a decisive drawback for predicting health-related behaviour.[49] Moreover, the model is based on cognitive processes and level of behaviour change, not taking into consideration the emotional variables such as fear and mood. The factor of fear brings in another theory named the Extended Parallel Process Model (EPPM).[15]

The Extended Parallel Process Model explains how efficacy beliefs and fear of a health threat combine to determine behavioural decisions, hence the model is also known as Threat Management or Fear Management. [50] The degree to which a patient with CKD feels threatened by the disease determines his or her motivation to engage with medication, dialysis and the recommended dietary and fluid controls. Basically, fear of having the $\mathrm{CKD}$ causes patients to adopt adherence strategies to deal with their health risk. Nevertheless, a study on the application of the theory revealed physicians with higher perceived threat to patients and efficacy to have higher probability of intentions and behaviour to test their patients' level of kidney functioning.[50] There is a need to replicate this study[50] to patients with CKD to assess their perceptions of the threats and efficacy of adherence to medication, dialysis, and fluid and dietary restriction.

Social Cognitive Theory Social Cognitive Theory is a behavioural prediction theory that represents a clinical approach to health behaviour change. [51] In this approach human motivation and actions are based on three types of expectancies namely situation-outcome, action-outcome and perceived self-efficacy.[51]The Social Cognitive Theory has been used in the prediction of health behaviours which include prevention, health promotion and the modification of unhealthy lifestyles.[51]

Situation-outcome entails beliefs about consequences that will occur without interfering personal action whilst action-outcome includes the belief that a given behaviour will result in a given outcome.[52] Selfefficacy expectancy is the belief that a type of behaviour is or is not within an individual's control, therefore an individual who is not capable of performing a particular adherence behaviour is regarded as self-efficacy lacking.[53] Adherence to medication requirements or suggested treatment is related to the self-regulatory belief. A study by Patterson et al. revealed positive significant relationships between physical activity behaviours and the constructs of Social Cognitive Theory namely self-efficacy, outcome expectations and self-regulation among dialysis patients.[54] This highlights the importance of using Social Cognitive Theory in explaining the physical activity behaviours in the dialysis population. [54]

Key concepts associated with renal failure patients include personal characteristics, emotional coping, behavioural capacity, self-efficacy, expectations and reinforcement.[55] Physical, social, cultural, economic and political factors can influence and predict adherence behaviours in Chronic Renal Failure patients, [55] and good adherence behaviours in renal failure patients can predict a reduction in complications of the disease. However, as the model has a wide-range of focus it is difficult to fully predict adherence behaviours. Currently selected parts of the theory are used and this poses questions regarding the applicability of the theory in predicting and improving adherence behaviours among patients with kidney disease.

Trans-theoretical Model Trans-theoretical Model based research incorporates behaviour change such as medication adherence.[13] Medication nonadherence behaviours are paramount in clinical and public health as they are associated with increased morbidity, increased mortality and reduced quality of life.[56] García-Llanaet al. revealed improved adherence behaviours in advanced CKD patients after the application of individual psycho-educational intervention programmes based on motivational interviewing and using the Stages of Change Model.[57] A Lifestyle Modification Programme based on the readiness to change health-promotion lifestyle behaviours was applied to CKD patients in the early stages of the disease. The results of this intervention revealed improved diet behaviour modifications showing the applicability of the components of Transtheoretical Model in improving adherence behaviours among CKD patients.[57] 
According to Tran's Theoretical Model, behaviour change relates to a process as opposed to an event and it provides important tools in research and intervention studies. The model allows interventions to be developed according to individual needs,[58] however, when using this model the large-scale implementation of interventions is complicated and costly, as well as time consuming. The use of this model is thus contraindicated in situations where rapid behaviour change is needed. Adherence behaviours to prescribed treatment among CKD patients require rapid behaviour change for positive treatment outcomes; therefore, this model is not feasible for promoting adherence among the population under study.

Health Belief Model The Health Belief Model is the most widely used social cognitive theory in health psychology; it basically predicts and explains health behaviours and that behaviour change is based on the balance of the barriers and benefits of health action. [59] According to this model, the perceived threat of a disease such as CKD is determined by the perceived seriousness and perceived susceptibility of and to that condition.[59] The effectiveness of any health behaviour is affected by its perceived benefits and barriers[8]. Apparently the Health Belief Model has included self-efficacy as a key factor and it is influenced by mediating variables such as demographic, structural and social variables.[60]

Elliot et al. did a descriptive study to establish any relationships between modifying factors, individual health beliefs and haemodialysis patients' adherence to a low-phosphorus diet. Modifying factors such as age, level of education and knowledge of the disease were found to be associated with dietary adherence, and individual health beliefs like self-efficacy to execute positive behaviours and the perceived benefits thereof were also found to be associated with dietary adherence. [61] Therefore, understanding of modifying factors and individual health beliefs yields positive dietary adherence among haemodialysis patients.[61]

According to this model four main beliefs influence adherence to regimens, namely the perceived benefits thereof, perceived barriers, susceptibility to illness, and the severity of the outcome of non-adherence. [62] In the studies that were done using the Health Belief Model to predict adherence, the predictors for adherence were revealed to be the benefits of treatment and disease threat.[63] Using the same model, Wileman et al. found that patients' beliefs regarding phosphate binding medications influenced their compliance/ adherence.[64] Fung et al. used the Health Belief Model to understand the psychosocial influences of nonadherence behaviours on peritoneal dialysis patients and the perceived benefits, perceived barriers and efficacy beliefs were found to predict non-adherence behaviours in this population.[65]

Becker et al. defined cues to action as factors that force an individual to make informed decisions about certain health related matters[8] meaning the strategies that activate readiness to take up the recommended health behaviour. With this view, peer support, family support and awareness about complications related to non-adherence are some of the factors or cues to action that are paramount in facilitating adherence in CKD population.[42] Norman and Connor identified sick role behaviours as compliance with the recommended medical regimens after diagnosis of an illness.[66] The Health Belief Model puts emphasis on the individual and ignores social and economic factors which directly impact on CKD treatment plans and affect the patients' engagement with integrated management plans. In addition, this model has no role for emotional factors such as fear and denial, [8] and these factors are predominant in CKD patients because of the nature of their disease.

\section{Conclusion}

A number of models have been applied in predicting and improving long-term medication adherence, particularly for patients suffering from CKD. However, among these no single model has been seen to adequately predict and improve the adherence of CKD patients because each has its own advantages and disadvantages. More research is needed to apply and test other models of care like the PASS Model, the Chronic Care Model and the Health Promotion Model to determine their applicability for predicting and improving adherence in the CKD population. Moreover, predicting and improving adherence behaviours needs interventions to be formulated based on the uniqueness of the CKD patients, the nature of the disease condition itself and the complex integrated management which entails dialysis, medication and fluid and dietary restriction.

\section{Limitations of the review}

- Few studies were found on the models and theories of care during the literature search from 2000 to 2017.

- There was a possibility of information bias since the review only focused on articles that had been published in peer review journals. 


\section{References}

1. Levin A, Stevens P, Bilous R, Coresh J, Francisco A De, Jong P De, et al. Kidney Disease: Improving Global Outcomes (KDIGO) CKD Work Group. KDIGO 2012 clinical practice guideline for the evaluation and management of chronic kidney disease. Kidney Int Suppl. 2013;3:1-50.

2. Geldine CG, Bhengu B, Manwere A. Adherence of adult Chronic Kidney Disease patients with regard to their dialysis, medication, dietary and fluid restriction. Adhésion de patients adultes atteints de maladie rénale chronique en ce qui concerne leur dialyse , leurs médicaments, leur régime alimentaire. Res J Heal Sci. 2017;5:3-17

3. Richard C. Self-care management in adults undergoing haemodialysis. Nephrol Nurs J. 2006;33:387.

4. Chironda G, Bhengu B. Contributing factors to nonadherence among chronic kidney disease (CKD) patients: a systematic review of literature. Medical \& Clinical Reviews. 2016;2(04):1-9.

5. Graham J. Nursing theory and clinical practice: how three nursing models can be incorporated into the care of patients with end stage kidney disease. CANNT J. 2006;16:28-31.

6. Michie S, Abraham C. Interventions to change health behaviours: evidence-based or evidenceinspired? Psychol Health. 2004;19:29-49.

7. Horne R, Weinman J. Predicting treatment adherence. Adherence to Treatment in Medical Conditions. Lynn Myers Kenny Midence. 1998;Apr 14:25-50.

8. Becker M, Maiman L, Kirscht J, Haefner D, Drachman R, Taylor D. Patient perceptions and compliance: recent studies of the health belief model. Compliance Heal care. 1979;8:78-109.

9. Bandura A, Simon K. The role of proximal intentions in self-regulation of refractory behavior. Cognit Ther Res. 1977;1:177-93.

10. Montano D, Kasprzyk D. Theory of reasoned action, theory of planned behavior, and the integrated behavioral model. Health behavior: Theory, research and practice. Heal Behav Heal Educ. 2015;

11. Sheppard BH, Hartwick J, Warshaw PR. The theory of reasoned action: A meta-analysis of past research with recommendations for modifications and future research. J Consum Res. 1998;325-43.

12. Orem D. A concept of self-care for the rehabilitation client. Rehabil Nurs. 1985;10:33-6.

13. Prochaska J. Transtheoretical model of behavior change. Encycl. Behav. Med. Springer New York; 2013.
14. Leventhal H, Phillips L, Burns E. The CommonSense Model of Self-Regulation (CSM): A dynamic framework for understanding illness selfmanagement. J Behav Med. 2016;39:935-46.

15. Sahbaei F, Jafari R, Fesharaki M. Evaluation the Drug Regime Adherence Based on the Extended Parallel Process Model in Patients with Hypertension Referred to the Hospitals Affiliated to Islamic Azad University, Branch of Tehran Medical Sciences. nternational J Med Res Heal Sci I. 2016;5:276-81.

16. Sabaté E. Adherence to long-term therapies: evidence for action. World Health Organization. World Heal. Organ. 2003.

17. Haynes R, Ackloo E, Sahota N, McDonald H, Yao X. Interventions for enhancing medication adherence. Cochrane Libr. 2008;

18. T Browne J, Merighi R. Barriers to adult hemodialysis patients' self-management of oral medications. Am J Kidney Dis. 2010;56:547-57.

19. McManus M. Illness representation and medication adherence of patients with chronic kidney disease. 2012.

20. J Rees, Chilcot J, Donnellan W, Soulsby L. Exploring the nature of illness perceptions in people with endstage kidney disease. J Ren Care. 2018;44:19-29.

21. Clarke A, Yates T, Smith A, Chilcot J. Patient's perceptions of chronic kidney disease and their association with psychosocial and clinical outcomes: a narrative review. Clin Kidney J. 2016;9:494-502.

22. Hagger M, Orbell S. A meta-analytic review of the common-sense model of illness representations. Psychol Heal. 2003;18:141-84.

23. Knowles S, Swan L, Salzberg M, Castle D, Langham R. Exploring the relationships between health status, illness perceptions, coping strategies and psychological morbidity in a chronic kidney disease cohort. Am J Med Sci. 2014;348:271-6.

24. Lin C, Chen M, Hsieh H, Chang S. Illness representations and coping processes of Taiwanese patients with early-stage chronic kidney disease. J Nurs Res. 2013;21:120-8.

25. Wu C, Lin C, Hsieh H, Chang S. Lived experiences and illness representation of Taiwanese patients with late-stage chronic kidney disease. J Health Psychol. 2016;21:2788-98.

26. Vélez-Vélez E, Bosch R. Illness perception, coping and adherence to treatment among patients with chronic kidney disease. J Adv Nurs. 2016;72:849-63.

27. McKillop G, Joy J. Patients'experience and perceptions of polypharmacy in chronic kidney disease and its impact on adherent behaviour. J Ren Care. 2013;39:200-7. 
28. Meuleman Y, Goeij M de, Halbesma N, Chilcot J, Dekker F, Dijk S van. PREPARE-2 Study Group. Illness perceptions in patients on predialysis care: associations with time until start of dialysis and decline of kidney function. Psychosom Med. 2015;77:846-54.

29. O'Connor S, Jardine A, Millar K. The prediction of self-care behaviors in end-stage renal disease patients using Leventhal's Self-Regulatory Model. J Psychosom Res. 2008;65:191-200.

30. McManus M. Illness representation and medication adherence of patients with chronic kidney disease. Indiana Univ. 2011.

31. Brandes K, Mullan B. Can the common-sense model predict adherence in chronically ill patients? A metaanalysis. Health Psychol Rev. 2014;8:129-53.

32. Ajzen I. Models of human social behavior and their application to health psychology. Psychol Heal. 1998;13:735-9.

33. Fleming M, Bapat S, Varisco T. Using the theory of planned behavior to investigate community pharmacists' beliefs regarding engaging patients about prescription drug misuse. Res Soc Adm Pharm. 2018; Oct 28.

34. Engel G. The need for a new medical model: a challenge for biomedicine. Holist Med. 1989;4:3753.

35. Fincham D, Kagee A, Moosa R. Dietary and fluid adherence among haemodialysis patients attending public sector hospitals in the Western Cape. South African J Clin Nutr. 2008;21:7-12.

36. Rich A, Brandes K, Mullan B, Hagger M. Theory of planned behavior and adherence in chronic illness: a meta-analysis. J Behav Med. 2015;38:673-88.

37. Ingabire C, Kateera F, Hakizimana E, Rulisa A, Muvunyi C, Mens P, et al. Determinants of prompt and adequate care among presumed malaria cases in a community in eastern Rwanda: a cross sectional study. Malar J. 2016;15:227.

38. Sutton S. Predicting and explaining intentions and behavior: How well are we doing?. J Appl Soc Psychol. 1998;28:1317-38.

39. See E, Alrukhaimi M, Ashuntantang G, Bello A, Bellorin-Font E, Gharbi M, et al. Global coverage of health information systems for kidney disease: availability, challenges, and opportunities for development. Kidney Int Suppl. 2018;8:74-81.

40. Lederer S, Ruggiero L, Sisen N, Epain L, O'Connor K, Wang Y, et al. The National Kidney Foundation of Illinois Kidney Mobile: a mobile resource for community based screenings of chronic kidney disease and its risk factors. BMC Nephrol.
2018;19:295.

41. Adejumo OA, Akinbodewa AA, Iyawe IO, Emmanuel A, Ogungbemi O. Assessment of knowledge of chronic kidney disease among nonnephrology nurses in Akure, South-West Nigeria. Saudi J Kidney Dis Transpl. 2018;29:1417-23.

42. Chironda $G$, Bhengu B. Motivators of adherence to integrated management among patients with chronic kidney disease: A qualitative study. Nurs Health Sci. 2018;Sep 7.

43. Unsar S, Erol O, Mollaoglu M. The self $\square$ care agency in dialyzed patients. Dialysis \& transplantation. 2007;36:57-70.

44. Bahadori M, Ghavidel F, Mohammadzadeh S, Ravangard $\mathrm{R}$. The effects of an interventional program based on self-care model on health-related quality of life outcomes in hemodialysis patients. J Educ Health Promot. 2014;3.

45. Jahanpeyma P, Akbari M. The Effect of Orem's Self-care Education on Interdialytic Weight and Blood Pressure Changes in Hemodialysis Patients. Int J Med Res Heal Sci. 2016;5:294-9.

46. Castro E, Regenmortel, Van T, Vanhaecht K, Sermeus W, Hecke A Van. Patient empowerment, patient participation and patient-centeredness in hospital care: a concept analysis based on a literature review. Patient Educ Couns. 2016;99:1923-39.

47. Hale J, Householder B, Greene K. The theory of reasoned action: Developments in theory and practice. 2003.

48. Baranowski T. Beliefs as motivational influences at stages in behavior change. Int Q Community Health Educ. 1992;13:3-29.

49. Dutta-Bergman M. Theory and practice in health communication campaigns: A critical interrogation. Health Commun. 2005;18:103-22.

50. Roberto A, Goodall C. Using the extended parallel process model to explain physicians' decisions to test their patients for kidney disease. J Health Commun. 2009;14:400-12.

51. Bandura A. Health promotion from the perspective of social cognitive theory. Psychol Heal. 1998;13:623-49.

52. Schwarzer R, Luszczynska A. Social cognitive theory. Predicting health behaviour. 2005; Jul 1:127-69.

53. Schwarzer R, Luszczynska A. Self-beliefs and selfregulation in health behavior change. Self-Concept, Motivation and Identity: Underpinning Success with Research and Practice. 2015; Jun 17:2011.

54. Patterson M, Umstattd, Meyer M, Beaujean A, Bowden R. Using the social cognitive theory to 
understand physical activity among dialysis patients. Rehabil Psychol. 2014;59:278.

55. Baranowski T, Lin L, Wetter D, Resnicow K, Hearn M. Theory as mediating variables: Why aren't community interventions working as desired?. Ann Epidemiol. 1997;7:89-95.

56. Clark S, Farrington K, Chilcot J. Nonadherence in dialysis patients: prevalence, measurement, outcome, and psychological determinants. Semin Dial. 2014;27:42-9.

57. García-Llana H, Remor E, Peso G del, Celadilla O, . RS. Motivational interviewing promotes adherence and improves wellbeing in pre-dialysis patients with advanced chronic kidney disease. J Clin Psychol Med Settings. 2014;21:103-15.

58. Friman M, Huck J, Olsson L. Transtheoretical model of change during travel behavior interventions: an integrative review. Int J Environ Res Public Health. 2017;14:581.

59. Green E, Murphy E. Health belief model. Wiley Blackwell Encycl. Heal. illness, Behav. Soc. 2014.

60. Skinner C, Tiro J, Champion V. The health belief model. Health behavior: theory, research, and practice. 5th ed. San Francisco (US): Jossey-Bass; 2015.

61. Elliott J, Ortman C, Almaani S, Lee Y, Ordan J. Understanding the associations between modifying factors, individual health beliefs, and hemodialysis patients' adherence to a low-phosphorus diet. J Ren Nutr. 2015;25:111-20.

62. Fenton N. The adolescent health belief model: Conceptalizing cognitive factors that influence medication non-adherence among adolescents. Univ. North Carolina Chapel Hill. 2014.

63. Higgins. E. Value from hedonic experience and engagement. Psychol Rev. 2006;113:439.

64. Wileman V, Farrington K, Wellsted D, Almond M, Davenport A, Chilcot J. Medication beliefs are associated with phosphate binder non $\square$ adherence in hyperphosphatemic haemodialysis patients. $\mathrm{Br} \mathrm{J}$ Health Psychol. 2015;20:563-78.

65. Fung T, Ng Y, Lam M, Lee K. Psychosocial Factors Predict Nonadherence to PD Treatment: A Hong Kong Survey. Perit Dial Int. 2017;37:331-7.

66. Norman P, Conner M. The theory of planned behaviour and binge drinking: Assessing the 